\title{
Phylogenies predict compensatory density dependence in coral-reef fisheries
}

\author{
Peter Houk ${ }^{1}$, Sarah Lemer ${ }^{1}$, Dalia Hernandez-Ortiz ${ }^{1}$, and Javier Cuetos-Bueno ${ }^{2}$ \\ ${ }^{1}$ University of Guam \\ ${ }^{2}$ The Nature Conservancy
}

August 4, 2020

\begin{abstract}
Population models are based upon the ideology that removing large, old individuals provides space for young, fast-growing counterparts that can maximize (fisheries) yields while maintaining population and ecosystem stability. Yet, we revealed that compensatory density dependence only existed for $49 \%$ of target coral-reef fishes exposed to growing fishing pressure across Pacific islands. Remaining species slowly disappeared from landings and reefs with limited population replenishment. To understand these remarkable differences, we constructed phylogenies for dominant fish families and discovered that large patristic distances between sister species, or greater isolation, predicted size-and-age truncation. Isolated species appeared to have greater niche dominance or breadth, supported by their faster growth rates and group foraging behavior. In contrast, closely related species may have more restricted, realized niches that led to their disappearance and replacement. Phylogenetic attributes offered novel guidance to proactively manage multispecies fisheries and improve our understanding of ecological niches and ecosystem stability.
\end{abstract}

\section{Introduction}

Maintaining sustainable fish stocks is complicated because ten-to-hundreds of target species coexist and the daunting task of selecting species for formal management has been equated to a form of triage that fisheries managers are faced with (Levin \& Stunz 2005; Patrick \& Link 2015). Desirable stock assessments that estimate population sizes, fish size-and-age structures, and catch rates are not feasible for small and disconnected multispecies fisheries, such as coral-reef fisheries. Instead, data-poor approaches take representative snapshot(s) of size-and-age structures, and assess the degree to which compensatory density dependence can replenish stocks based upon several size-related metrics of fecundity and recruitment (Nadon et al.2015; Prince et al. 2015; Eikeset et al. 2016). These approaches assume that density dependence is the primary driver of population replenishment, which is well supported by studies demonstrating how density dependence begets ecosystem stability, even in complex food webs (McCann et al.1998; Berlow et al. 2009; Houk et al. 2018b). However, the expected replacement of large, old fish with mid-sized younger counterparts has not had ubiquitous support, especially among coral-reef fisheries. The causes of species variability and consequences of treating species similarly forms the basis for our study.

Recently, (Houk et al. 2018a) documented changes in abundances and size structures across 25 years of exploitation in a coral-reef fishery and found contrasting responses among herbivore/detritivore species with similar maximum body-sizes and growth rates (Figure 1). Species were classified as 'winners' if they persisted as major contributors to landings over decades despite having size-and-age truncation. In contrast, species were classified as 'losers' if they slowly disappeared from landings while having little-to-no shifts in their size structure. Similar responses have now been reported from many Pacific islands based upon both fisheriesdependent and fisheries-independent data (Houk et al. 2012; Houk \& Musburger 2013; Houk et al. 2015; McLean et al. 2016; Houk et al. 2017; Cuetos-Bueno et al. 2018). 
These disparate responses have remarkable consequences for fisheries management and can improve our contextual understanding of ecological niches. For instance, stock assessments based upon size structures mayincorrectly recommend that no management is required for 'losing' species while they disappear from landings and reefs, so long as little-to-no size-and-age truncation is observed (Lorenzen \& Enberg 2002; Hordyk et al. 2014; Nadon et al. 2015; Prince et al. 2015). More broadly, the disparate density dependence responses may also predict niche attributes, such as dominance and breadth, and lead to better predictions of ecosystem services and stability. Our goal was to investigate phylogenetic attributes as a proactive and inexpensive means towards predicting compensatory density dependence responses.

Recent studies have seen an increase in the combined use of ecological data and phylogenetic information to understand the structure and assembly of communities and predict the vulnerability of certain taxa to overexploitation (Jennings et al.1999b; Godoy et al. 2014). We hypothesized that phylogenies may help predict the relative strength of density dependence responses within a diverse coral-reef fishery and identify 'winning' and 'losing' species proactively. Our hypothesis builds upon Darwin's observation that competition should be stronger between closely related species with more similar traits (Darwin 1859), potentially as a result of higher realized niche partitioning, and lead to low species persistence with exploitation. In contrast, we hypothesized that greater phylogenetic isolation, defined by larger distances between sister species, may equate to stronger density dependence and persistence, and might infer greater niche dominance or breadth.

Our hypothesis was tested by combining an extensive network of fisheries-dependent datasets from many Pacific islands with an objective measure of phylogenetic isolation. Genetic material was collected from primary target species that accounted for $90 \%$ of the landings within four dominant families common to coralreef fisheries in the Pacific: parrotfishes, surgeonfishes, snappers, and emperorfishes. We then examined novel relationships between phylogenetic isolation and species-based responses to fishing pressure and revealed a proactive means towards species-based management before stocks show signs of decline.

\section{Brief Methods}

\section{Study area and sampling designs}

Fisheries-dependent datasets and fish fin clips were gathered from 8 jurisdictions across Micronesia, tropical North Pacific: Guam, Commonwealth of the Northern Mariana Islands (Saipan and Tinian islands), Yap, Pohnpei, Chuuk, Kosrae, the Republic of Palau, and the Republic of the Marshall Islands (Majuro and Arno atolls). Fisheries dependent datasets were derived from intensive sampling efforts through time and across islands (Houk et al. 2012; Houk et al. 2017; Cuetos-Bueno et al. 2018; Houk et al. 2018a; Rhodes et al. 2018; Cuetos-Bueno et al. 2019). Guam data were collected through a governmental creel-survey program has existed since the mid 1980's providing a novel timeseries across decades (Houk et al. 2018a). Data from other islands were collected across representative fishing gears and environmental regimes with daily visits to markets for one year. These surveys provided between 60,000 and over 200,000 fish measurements per island-year and were ideal for assessing size structures and proportional contributions. We examined the most abundant four families identified in the datasets: snappers (lutjanids), emperorfishes (lethrinids), surgeonfishes (acanthurids), and parrotfishes (scarine-labrids) (Houk et al.2017; Cuetos-Bueno et al. 2018; Houk et al. 2018a; Rhodes et al. 2018; Cuetos-Bueno et al. 2019). We further identified species that comprised $90 \%$ of the landings within each family as dominant target species.

\section{Responses to fishing pressure}

Target species were examined for density dependence using the following sequential tests based upon data availability (see Supplemental Extended Methods ). (1) The statistical effect size for decreasing size structures through time was compared to the effect size for decreasing proportional contributions through time using a 25-year dataset from Guam, where time was an indiscriminate fishing gradient (Houk et al. 2018a). (2) The skewness of each island population was regressed against the human populations, using human presence as an exploitation gradient, with significance (i.e., P-values) and model stability (i.e., normally distributed residuals) required. (3) Size structures from 2 or more snapshot studies from individual islands were examined using a boot-strapping approach that created histograms from 100 randomly sampled fish, 
1000 times, and calculated a vector of skewness values that was required to have $95 \%$ of the data above 0 . (4) Size structures were examined using the same boot-strapping procedure but from 1 island only. Species were classified as having strong density dependence when declining size structures existed across space and/or time, or if positively skewed size structures in snapshot assessments. Yet, we weighted the confidence of species classifications sequentially based upon methods, 1-highest to 4-lowest, and compared results across assessment methods (Table S1).

\section{Statistical analyses}

Potential relationships between phylogenetic isolation and species-based responses to fishing pressure were assessed using a series of generalized linear models (GLM) and generalized linear mixed models (GLMM) that included family as a potential random factor (Bates et al. 2015). Model fit was assessed based upon comparing the resultant deviance estimates to null counterparts, with Z-values and P-values generated based upon the confidence intervals that indicated effect size and significance, respectively. When building models, we included a term for body-size to remove any potential effects that body-size may have on phylogenetic isolation and species-based responses (Figure S1).

We last assessed if 'winning' species with population persistence had growing proportional contributions to annual landings with growing human populations and commercialization of fisheries. 'Winning' species with large phylogenetic isolation above the binomial model switchpoint were regressed against human populations and commercial landings using linear least-squares regressions, while assessing P-values, effect sizes, and residual normality.

\section{Results}

Forty-seven species of reef fish contributed to $90 \%$ of the landings within the four study families, including $10,13,12$, and 22 species respectively from the snappers, emperorfishes, surgeonfishes, and parrotfishes. Among these species, there was sufficient fisheries-dependent and genetic data to include 37 species in the GLMM and GLM analyses (7, 6, 8, and 16 species from the respective families), defining our list of dominant target species (Table S1). These dominant species contributed to $60 \%$ of the fisheries landings across the study islands combined, with individual island contributions ranging between $53 \%$ and $70 \%$. Analyses of fisheries-dependent datasets revealed that 18 of the dominant species, or $49 \%$, were defined as having size/age truncation $(3,4,5$, and 6 , for the respective families). In confirmation, 13 out of 16 species with enough data to assess whether size/age truncation existed using two or more of the outlined methods provided the same results (Table S1). Thus, the approaches used to classify species provided similar results in most cases.

The phylogenetic analyses recovered similar tree topologies for each family, allowing us to confidently identity sister clades for all species except two parrotfishes (Figure S2). GLM modeling revealed that phylogenetic isolation was the best predictor of whether target species showed a size/age truncated response to fishing pressure (Z-value $=2.7, \mathrm{P}=0.007$, generalized linear model for all families combined, Figures 2 and 3 ). Larger phylogenetic isolation predicted the size/age truncated response. Interestingly, including family as a random factor did not significantly improve the model fit, suggesting a similar switchpoint existed across families (Figure 3). Yet, surgeonfishes and parrotfishes began showing size-based responses at smaller patristic distances compared to snappers and emperorfishes, representing the few species with observed size-based responses and phylogenetic isolation slightly below the model switchpoint (species $\mathbf{3}, 5, \mathbf{7}, 30$, and 31 in Figure 3, bold indicates the two parrotfish species with weak nodal support). In contrast, three snappers did not have size-based responses observed despite having phylogenetic isolation slightly above $10 \%$ and strong nodal support $(25,28$, and 29, Figure 3$)$. There was only one species with phylogenetic isolation significantly greater than the model switchpoint but without size/age truncation observed,Cetoscarus ocellatus .

While consistent body-size classifications existed across the fish families (Figure S1), body-size had no significant association with phylogenetic isolation using raw values or classifications of maximum lengths. Further, body-size in combination with phylogenetic isolation did not predict whether species exposed to fishing pressure would become size/age truncated. 
We last revealed a growing proportional contribution to annual landings with human populations for 'winning' species that became more prolific despite declining size structures (Figure 4). Similarly, we revealed a positive relationship between the proportional contribution of 'winning' species and commercial fish landings, even as fisheries appeared to exceed their maximum yields and become overexploited (Figure S3).

\section{Discussion}

The present study provided context to the common assumption that density dependence is the primary driver of fish population dynamics. We demonstrated that $51 \%$ of target coral-reef fishes did not show the expected compensatory density dependence response when exposed to fishing pressure, but instead have been slowly disappearing from landing and reefs (Houk et al. 2015; McLean et al. 2016; Houk et al. 2017; Cuetos-Bueno et al. 2018; Houk et al. 2018a; Houk et al. 2018b). Previous studies have found that the smaller of two closely related sister species will replace the larger counterpart in landings as fishing pressure grows (Jennings et al.1999a; Jennings et al. 1999b). However, we add broader context showing that (i) replacements can also occur between fish with similar maximum body sizes, and most importantly, (ii) there was a phylogenetic distance threshold beyond which compensatory density dependence became stronger than species replacements. While high sensitivity to fishing pressure has been documented for the largest reef fish with body-sizes approaching $1 \mathrm{~m}$, reef-associated sharks, and other iconic megafauna (Martin et al. 2016; Hamilton et al. 2019), we emphasize that disparate sensitivities existed among common target species from four families that are essential for both food security and ecosystem resilience across the Pacific (Bellwood et al. 2012; Mumby et al. 2013; McLean et al. 2016).

Darwin's foundational hypothesis proposed that more closely related species would be in stronger competition with each other and therefore reduce access to resources, or reduce niche dominance (Darwin 1859). If so, smaller phylogenetic isolation may infer greater present-day competition and realized-niche partitioning of available resources, as seen with protist species and Cuban lizards (Knouft et al. 2006; Violle et al. 2011), and hypothesized generally by Hutchinson (Hutchinson 1959). In contrast, we hypothesize that greater phylogenetic isolation may indicate increased niche breadth that leads to species persistence. In support, we contrast two parrotfishes, Hipposcarus longiceps and Chlorurus microrhinos, and two surgeonfishes, Naso unicornis andAcanthurus xanthopterus, that had similar sizes-at-capture and asymptotic lengths. Growing fishing pressure has resulted in size/age truncation for H. longiceps and $N$. unicornis that had greater phylogenetic isolation, while C. microrhinos and A. xanthopterus slowly disappeared from landings with little change to their size structure. Interestingly, both $H$. longiceps and $N$. unicornis have larger than expected growth rates based upon standard body-size growth curves for their respective families (Choat et al. 2002; Taylor \& Choat 2014; Taylor et al. 2014), and both travel in large roving schools that afford greater access to resources and/or protection. In contrast, C. microrhinos has a small home range and notable morphological features that provide a competitive advantage to access a limited resource pool (Bellwood 1995; Lokrantz et al. 2008; Bonaldo \& Bellwood 2009), while less is known about A. xanthopterus . Thus, disparate responses to fishing pressure may equate to disparate differences in life-histories, diets, functional traits, and ecosystem services (Bellwood et al. 2012). If so, phylogenetic characteristics have the potential to proactively determine a suite of species attributes that can be used to understand ecosystem structure and stability, starting with why niche breadth and dominance may differ. Yet, more species-specific studies are needed to test this hypothesis.

Of immediate importance, the present phylogenetic distance thresholds predicted the presence of an institutional attribute of ecology and fisheries models, density dependence, and predicted when standard fisheries stock assessments may be misleading. These findings can be extended for proactive management guidance. Size-based regulations may be a central component of fisheries plans dealing with species that have strong compensatory density dependence. However, gear/quota/area policies may be more suitable for management plans addressing species that slowly disappear from landings will less, or no, change to their size structure. Therefore, we conclude that phylogenies offer novel and inexpensive guidance for improving data-poor multispecies fisheries management.

\section{Acknowledgements}


Research was funded by a National Fish and Wildlife Program Coral Reef Conservation grant provided to the authors. Sub-grants provided by the Micronesia Conservation Trust and a direct grant from the National Oceanic and Atmospheric Administration Saltonstall-Kennedy Fisheries Program to authors PH and JCB facilitated most of the fisheries-dependent data collection, along with contributions from other authors where referenced. We are grateful for conversations with and participation from all individual in the Micronesia coral-reef and fisheries monitoring programs, unfortunately too numerous to list.

\section{References}

1. Bates, D., Maechler, M., Bolker, B., Walker, S., Christensen, R.H.B., Singmann, H. et al. (2015). Package 'Ime4'. 12, 2.

2. Bellwood, D.J.M.B. (1995). Direct estimate of bioerosion by two parrotfish species, Chlorurus gibbus and C. sordidus, on the Great Barrier Reef, Australia. 121, 419-429.

3. Bellwood, D.R., Hoey, A.S. \& Hughes, T.P.J.P.o.t.R.S.B.B.S. (2012). Human activity selectively impacts the ecosystem roles of parrotfishes on coral reefs. 279, 1621-1629.

4. Berlow, E.L., Dunne, J.A., Martinez, N.D., Stark, P.B., Williams, R.J. \& Brose, U.J.P.o.t.N.A.o.S. (2009). Simple prediction of interaction strengths in complex food webs. 106, 187-191.

5. Bonaldo, R.M. \& Bellwood, D.R.J.M.B. (2009). Dynamics of parrotfish grazing scars. 156, 771-777.

6. Choat, J.H., Robertson, D.R.J.C.r.f.d. \& diversity in a complex ecosystem. Academic Press, S.D., California, USA (2002). Age-based studies. 57-80.

7. Cuetos-Bueno, J., Hernandez-Ortiz, D., Graham, C. \& Houk, P. (2018). Human and environmental gradients predict catch, effort, and species composition in a large Micronesian coral-reef fishery. PloS one , 13, e0198068.

8. Cuetos-Bueno, J., Hernandez-Ortiz, D. \& Houk, P. (2019). Co-evolution of "race-to-fish" dynamics and declining size structures in an expanding commercial coral-reef fishery.Reviews in Fish Biology and Fisheries , 29, 147-160.

9. Darwin, C. (1859). On the origin of species . Routledge.

10. Edgar, R.C. (2004). MUSCLE: multiple sequence alignment with high accuracy and high throughput.Nucleic acids research , 32, 1792-1797.

11. Eikeset, A.M., Dunlop, E.S., Heino, M., Storvik, G., Stenseth, N.C. \& Dieckmann, U. (2016). Roles of density-dependent growth and life history evolution in accounting for fisheries-induced trait changes. Proceedings of the National Academy of Sciences , 113, 15030-15035.

12. Godoy, O., Kraft, N.J. \& Levine, J.M.J.E.L. (2014). Phylogenetic relatedness and the determinants of competitive outcomes. $17,836-844$.

13. Hamilton, R.J., Hughes, A., Brown, C.J., Leve, T. \& Kama, W.J.C.R. (2019). Community-based management fails to halt declines of bumphead parrotfish and humphead wrasse in Roviana Lagoon, Solomon Islands. 38, 455-465.

14. Hordyk, A., Ono, K., Valencia, S., Loneragan, N. \& Prince, J. (2014). A novel length-based empirical estimation method of spawning potential ratio (SPR), and tests of its performance, for small-scale, data-poor fisheries. ICES Journal of Marine Science, 72, 217-231.

15. Houk, P., Camacho, R., Johnson, S., McLean, M., Maxin, S., Anson, J. et al. (2015). The Micronesia Challenge: Assessing the relative contribution of stressors on coral reefs to facilitate science-to-management feedback. 10.

16. Houk, P., Cuetos-Bueno, J., Tibbatts, B. \& Gutierrez, J. (2018a). Variable density dependence and the restructuring of coral-reef fisheries across 25 years of exploitation. Scientific reports, , 8, 5725 . 
17. Houk, P., Cuetos-Bueno, J., Kerr, A. \& McCann, K. (2018b). Linking fishing pressure with ecosystem thresholds and food web stability on coral reefs. Ecological Monographs , 88, 109-119.

18. Houk, P. \& Musburger, C.J.M.E.P.S. (2013). Trophic interactions and ecological stability across coral reefs in the Marshall Islands. 488, 23-34.

19. Houk, P., Rhodes, K., Cuetos-Bueno, J., Lindfield, S., Fread, V. \& McIlwain, J. (2012). Commercial coral-reef fisheries across Micronesia: a need for improving management. Coral reefs , 31, 13-26.

20. Houk, P., Tilfas, R., Luckymis, M., Nedlic, O., Ned, B., Cuetos-Bueno, J. et al. (2017). An applied framework to assess exploitation and guide management of coral-reef fisheries. Ecosphere, 8, e01727.

21. Hutchinson, G.E.J.T.A.N. (1959). Homage to Santa Rosalia or why are there so many kinds of animals? , 93, 145-159.

22. Jennings, S., Greenstreet, S.P. \& Reynolds, J.D. (1999a). Structural change in an exploited fish community: a consequence of differential fishing effects on species with contrasting life histories. Journal of Animal Ecology, 68, 617-627.

23. Jennings, S., Reynolds, J.D. \& Polunin, N.V. (1999b). Predicting the vulnerability of tropical reef fishes to exploitation with phylogenies and life histories. Conservation biology , 13, 1466-1475.

24. Knouft, J.H., Losos, J.B., Glor, R.E. \& Kolbe, J.J. (2006). Phylogenetic analysis of the evolution of the niche in lizards of the Anolis sagrei group. Ecology , 87, S29-S38.

25. Levin, P.S. \& Stunz, G.W. (2005). Habitat triage for exploited fishes: Can we identify essential "Essential Fish Habitat?". Estuarine, Coastal and Shelf Science, 64, 70-78.

26. Lokrantz, J., Nyström, M., Thyresson, M. \& Johansson, C.J.C.R. (2008). The non-linear relationship between body size and function in parrotfishes. 27, 967-974.

27. Lorenzen, K. \& Enberg, K. (2002). Density-dependent growth as a key mechanism in the regulation of fish populations: evidence from among-population comparisons.Proceedings of the Royal Society of London. Series B: Biological Sciences, 269, 49-54.

28. Martin, S.L., Van Houtan, K.S., Jones, T.T., Aguon, C.F., Gutierrez, J.T., Tibbatts, R.B. et al.(2016). Five decades of marine megafauna surveys from Micronesia. 2, 116.

29. McCann, K., Hastings, A. \& Huxel, G.R.J.N. (1998). Weak trophic interactions and the balance of nature. 395, 794-798.

30. McLean, M., Cuetos-Bueno, J., Nedlic, O., Luckymiss, M. \& Houk, P.J.P.o. (2016). Local stressors, resilience, and shifting baselines on coral reefs. 11 .

31. Mumby, P., Bejarano, S., Golbuu, Y., Steneck, R., Arnold, S., Van Woesik, R. et al. (2013). Empirical relationships among resilience indicators on Micronesian reefs. 32, 213-226.

32. Nadon, M.O., Ault, J.S., Williams, I.D., Smith, S.G. \& DiNardo, G.T. (2015). Length-based assessment of coral reef fish populations in the Main and Northwestern Hawaiian Islands. PLoS One, 10, e0133960.

33. Patrick, W.S. \& Link, J.S. (2015). Myths that continue to impede progress in ecosystem-based fisheries management. Fisheries, 40, 155-160.

34. Prince, J., Victor, S., Kloulchad, V. \& Hordyk, A.J.F.R. (2015). Length based SPR assessment of eleven Indo-Pacific coral reef fish populations in Palau. 171, 42-58.

35. Rhodes, K.L., Hernandez-Ortiz, D.X., Cuetos-Bueno, J., Ioanis, M., Washington, W. \& Ladore, R. (2018). A 10-year comparison of the Pohnpei, Micronesia, commercial inshore fishery reveals an increasingly unsustainable fishery. Fisheries Research , 204, 156-164. 
36. Ronquist, F., Teslenko, M., Van Der Mark, P., Ayres, D.L., Darling, A., Höhna, S. et al. (2012). MrBayes 3.2: efficient Bayesian phylogenetic inference and model choice across a large model space. Systematic biology , 61, 539-542.

37. Stamatakis, A. (2006). RAxML-VI-HPC: maximum likelihood-based phylogenetic analyses with thousands of taxa and mixed models. Bioinformatics , 22, 2688-2690.

38. Tamura, K., Peterson, D., Peterson, N., Stecher, G., Nei, M. \& Kumar, S. (2011). MEGA5: molecular evolutionary genetics analysis using maximum likelihood, evolutionary distance, and maximum parsimony methods. Molecular biology and evolution, 28, 2731-2739.

39. Taylor, B. \& Choat, J.J.J.o.f.b. (2014). Comparative demography of commercially important parrotfish species from Micronesia. 84, 383-402.

40. Taylor, B., Rhodes, K., Marshell, A. \& McIlwain, J.J.J.o.F.B. (2014). Age-based demographic and reproductive assessment of orangespine Naso lituratus and bluespine Naso unicornis unicornfishes. 85, 901-916.

41. Violle, C., Nemergut, D.R., Pu, Z. \& Jiang, L. (2011). Phylogenetic limiting similarity and competitive exclusion. Ecology letters, 14, 782-787.

Figures 


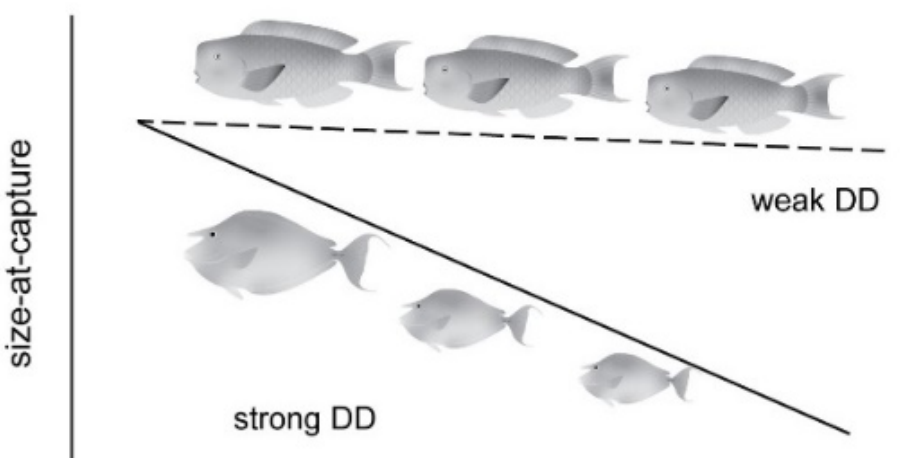

a)

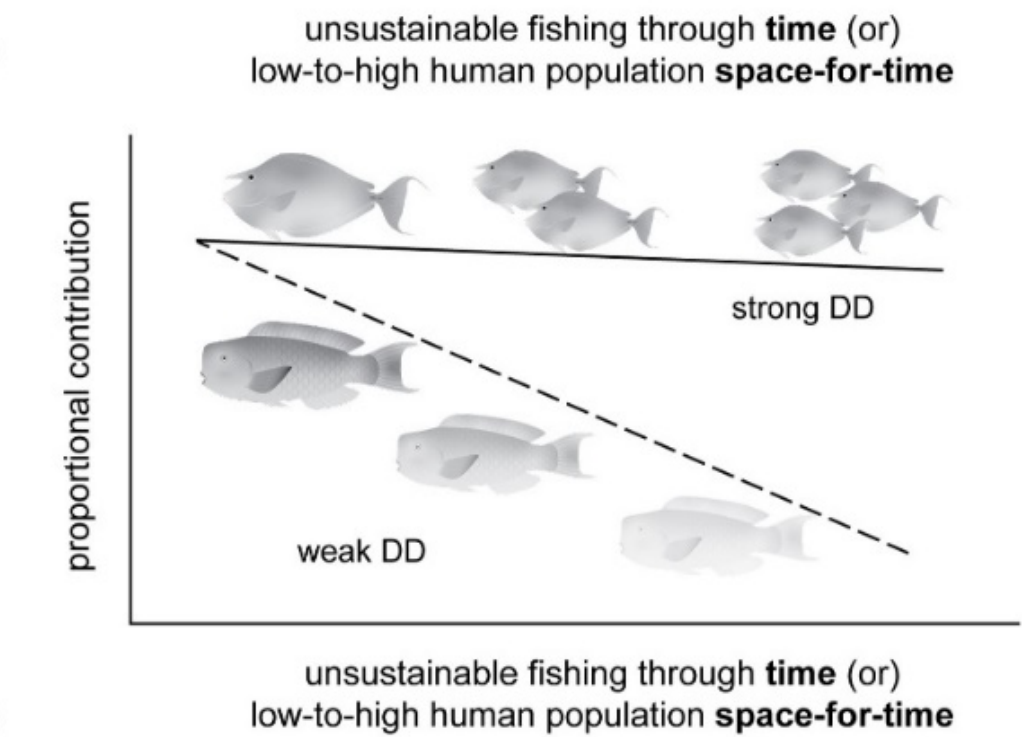

b) low-to-high human population space-for-time

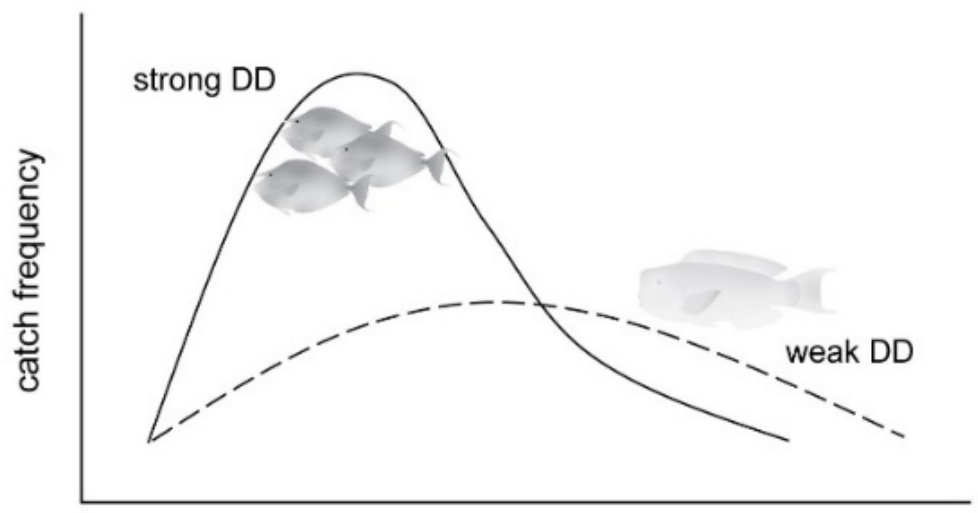

c)

size-at-capture snapshot study in exploited fishery

Figure 1. Differing species responses to fishing pressure observed from the Pacific study islands. Many 
species have declined in size with growing human presence, or fishing pressure, such as the unicornfish Naso unicornis (a). In contrast, species like the steephead parrotfish Chlorurus microrhinos have declined more in terms of their proportional contribution to landings than their size structure (b). These differing responses result in distinct catch-frequency histograms when snapshot studies are conducted (c).

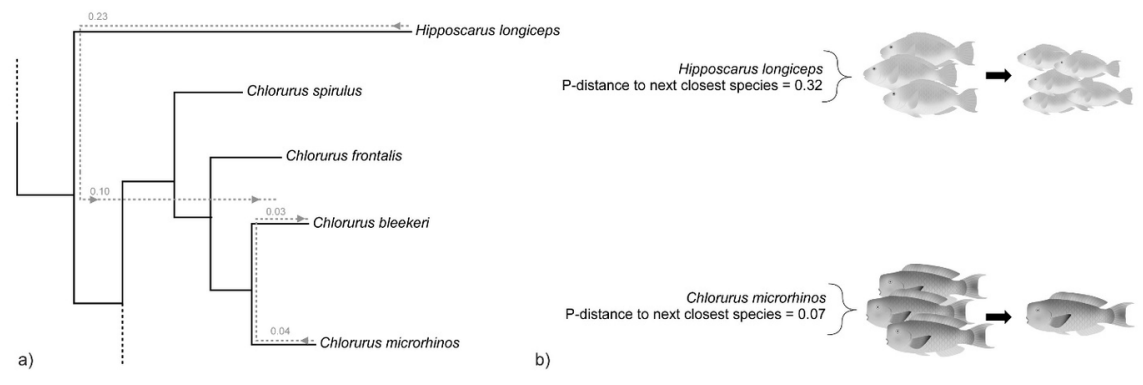

Figure 2 . Example of how patristic distances (P-distances) were inferred between sister species or sister clades. Subset of the phylogeny for parrotfishes showing P-distances for H. longicepsand C. microrhinos based upon distance to their sister species or clade (a). Species with large P-distances were observed to have stronger density dependence based upon fisheries dependent data (b-top), while species with smaller P-distances had weaker density dependence (b-bottom).

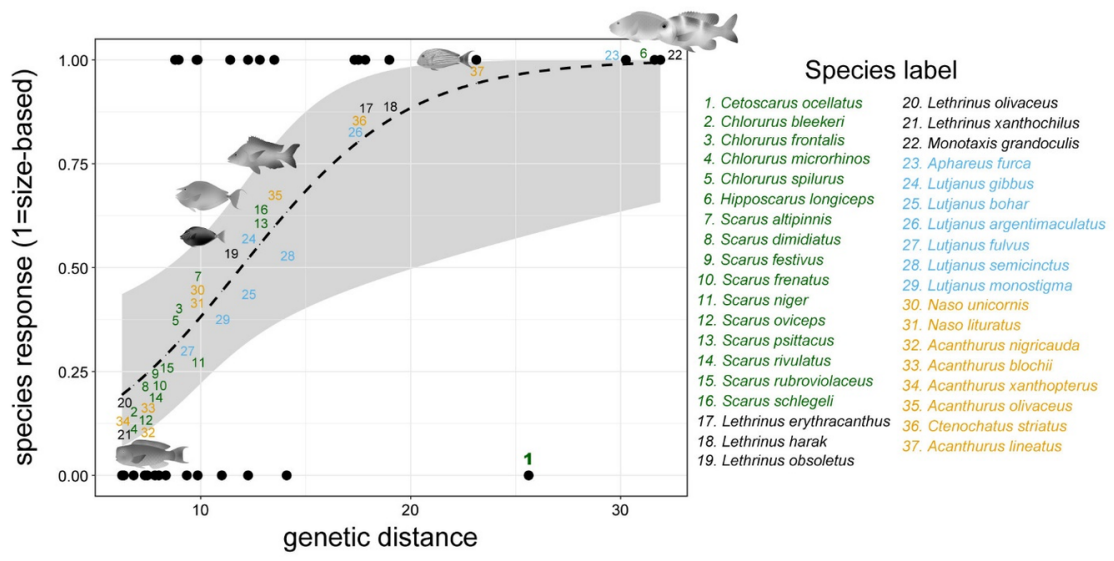

Figure 3 . Generalized linear modeling results highlighting the relationship between patristic phylogenetic distances and species responses to fishing pressure. Horizontal placement of numbers indicate where each species resides along the x-axis. Vertical placement of numbers on the bottom of the regression line represent species without size/age truncation responses, while number on top indicate size/age truncation responses were detected from fisheries-dependent datasets. The bold number (1) indicates the parrotfish, Cetoscarus ocellatus, that responded differently than expected to fishing pressure based upon its patristic distance. 


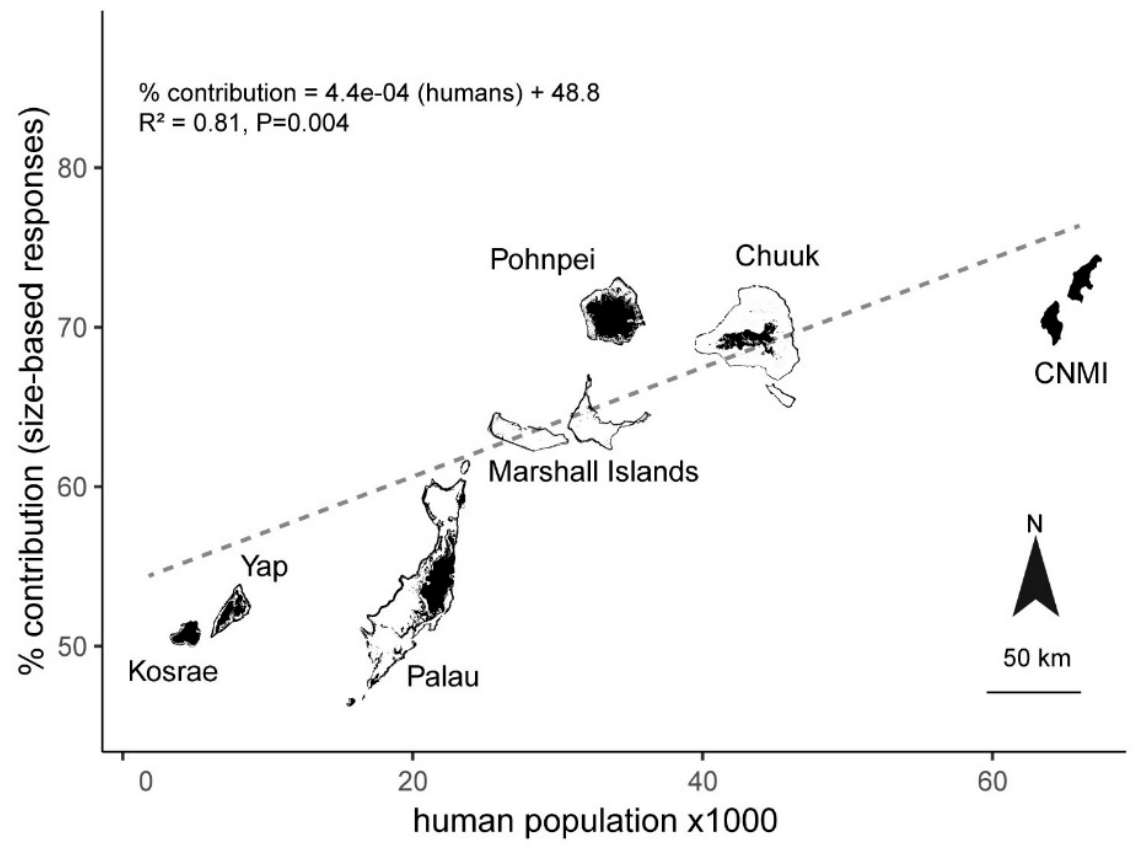

Figure 4 . Regression model highlighting the growing contribution of species with strong size-based responses to fishing pressure with growing human population. Island silhouettes showing land and shallow reefs represent the regression datapoints. Marshall Islands consisted of two atolls, Majuro and Arno (left and right, respectively). Commonwealth of the Northern Mariana Islands consisted of two islands, Saipan and Tinian (top and bottom, respectively). Exact locations of data points are the center of the island graphics. Scalebar is provided for comparative reference. 